\section{Seroprevalence of Chikungunya Virus after Its Emergence in Brazil}

\section{Patrick Gérardin, ${ }^{1}$ André Ricardo Ribas Freitas, ${ }^{1}$ Daouda Sissoko ${ }^{1}$}

Author affiliations: Centre Hospitalier Universitaire Réunion, Saint Pierre, France (P. Gérardin); Unité Mixte 134 Processus Infectieux en Milieu Insulare Tropical, Sainte Clotilde, France (P. Gérardin); São Leopoldo Mandic School of Medicine, Campinas, Brazil (A.R.R. Freitas); Biomerieux Africa Cluster, Abidjan, Côte d'Ivoire (D. Sissoko)

\section{DOI: https://doi.org/10.3201/eid2409.180724}

To the Editor: In their well-designed and timely serosurvey, Dias et al. provide evidence of high prevalence of East/Central/South African (ECSA) genotype chikungunya virus (CHIKV) (seropositivity rate $51.0 \%$ ) in population subsets of 2 urban communities in Bahia state, Brazil (1). The authors found a high proportion of asymptomatic CHIKV patients $(63.2 \% ; 268 / 424)$. In addition, the prevalence of chronic arthralgia among infected persons (26.4\%; $112 / 424$ ) was lower or within the expected range of previously reemerging clades of CHIKV, namely ECSA diverged (Indian Ocean lineage) or Asian lineage, respectively. However, a high proportion of the symptomatic participants in Dias et al. reported chronic symptoms lasting $>3$ months $(71.8 \% ; 112 / 156)$. We comment on these findings.

First, Dias et al. report that the selected locations were at the epicenter of the transmission area and, therefore, the data cannot be extrapolated to other cities. To better understand the dynamics of the disease, it would be useful to select locations more representative of other infected areas.

Second, the modest participation at the study locations $(66.5 \% ; 831 / 1250)$ could be related to using the more painful venipuncture method instead of a fingerstick to draw blood. In comparison, the participation rate was $\approx 80 \%$ in

${ }^{1}$ All authors contributed equally to this article. a Réunion Island serosurvey for CHIKV for which the fingerstick method was used (2). The participation level suggests the possibility of self-selection bias toward infected patients, who might be more interested in knowing their serologic status. Self-selection bias might explain the high proportion of symptomatic patients who self-reported having a chronic form of chikungunya.

Last, because of their unreliable discriminatory performance, using fever and arthralgia to identify symptomatic patients might have increased the proportion of patients misclassified as asymptomatic (i.e., patients with symptoms other than fever and arthralgia being falsely classified as negative) (3). These limitations being specified, the prevalence of chronic arthralgia among symptomatic patients in Dias et al. falls within the expected range of the Asian lineage of CHIKV, the other clade circulating in the Americas $(4,5)$, which confers external validity to the study.

\section{References}

1. Dias JP, Costa MDCN, Campos GS, Paixão ES, Natividade MS, Barreto FR, et al. Seroprevalence of chikungunya virus after its emergence in Brazil. Emerg Infect Dis. 2018;24:617-24. http://dx.doi.org/10.3201/eid2404.171370

2. Gérardin P, Guernier V, Perrau J, Fianu A, Le Roux K, Grivard P, et al. Estimating Chikungunya prevalence in La Réunion Island outbreak by serosurveys: two methods for two critical times of the epidemic. BMC Infect Dis. 2008;8:99. http://dx.doi.org/ 10.1186/1471-2334-8-99

3. Sissoko D, Ezzedine K, Moendandzé A, Giry C, Renault P, Malvy D. Field evaluation of clinical features during chikungunya outbreak in Mayotte, 2005-2006. Trop Med Int Health. 2010;15:600-7.

4. Chang AY, Encinales L, Porras A, Pacheco N, Reid SP, Martins KAO, et al. Frequency of chronic joint pain following chikungunya virus infection: a Colombian cohort study. Arthritis Rheumatol. 2018;70:578-84. http://dx.doi.org/10.1002/art.40384

5. Paixao ES, Rodrigues LC, Costa MCN, Itaparica M, Barreto F, Gérardin P, et al. Chikungunya chronic disease: a systematic review and meta-analysis. Trans R Soc Trop Med Hyg. 2018. Jul 11.

Address for correspondence: Patrick Gérardin, INSERM CIC 1410 Clinical Epidemiology, Centre Hospitalier Universitaire, Groupe Hospitalier Sud Réunion, BP 350, 97448 Saint Pierre CEDEX, Reunion, France; email: patrick.gerardin@chu-reunion.fr

\title{
Correction: Vol. 24, No. 8
}

The author list was incorrect in Death from TransfusionTransmitted Anaplasmosis, New York, USA, 2017 (R. Goel et al.), and a name was missing from the acknowledgments. Melissa M.
Cushing should have been listed as senior author. Ljljana V. Vasovic provided assistance with the article. The article has been corrected online (https://wwwnc.cdc.gov/eid/article/24/8/17-2048_article).

\section{Correction: Vol. 24, No. 9}

Several corrections to the text were needed in Phenotypic and Genotypic Characterization of Enterobacteriaceae Producing Oxacillinase-48-Like Carbapenemases,
United States (J.D. Lutgring et al.). The article has been corrected online (https://wwwnc.cdc.gov/eid/article/24/4/ 17-1377_article). 